\title{
Problems of Composition, Temporality and Change in Tracing the Common Agricultural Policy through Time
}

\author{
Adrian KAY and Robert ACKRILL
}

Investigating the reasons for change and continuity is central to any historical perspective on the Common Agricultural Policy (CAP). However, this investigation is often hampered by the problem of specifying the explanandum, or in social science language operationalising the dependent variable, 'the CAP'. What are the appropriate dimensions and scales at which to track the CAP through time? Policy has been described as a meso-level, whereas others recognise that policy also encompasses micro decisions. ${ }^{1}$ Peter Hall's framework of three levels of policy - paradigms, instruments, calibration - was the first effort to move description of policy change beyond a single variable and it remains the mainstay for most analyses of policy development. $^{2}$ This enduring impact attests to the originality of Hall in moving the description of policy change to stress the cognitive and normative dimensions of a policy alongside more formal, legalistic policy instruments. As Chris Elton in this volume sets out, the application of the Hall scheme to the CAP has encouraged scholars to be sensitive to how ideas rather than calculations of material self-interest may drive policy-making; and in raising questions about the relationship between ideas and material factors in CAP policy processes by stressing that policymakers work within a framework of beliefs that specifies goals and instruments, as well as the nature of the policy problems.

There are criticisms about the degree of sensitivity in Hall's framework to policy change; in particular, whilst the notion of a policy paradigm may provide some leverage in understanding the policy-making consequences of rare, epochal shifts such as the shift from Keynesianism to monetarism in the United Kingdom as in the original Hall article, there are doubts about its ability to account for episodes of substantial policy change that are significant beyond the 'normal' cycle of policy-making but nonetheless fall short of paradigm change. There is a significant policy space between small change (at the instrument and programme level) and big change (at the paradigmatic level).

A recent refinement of the Hall taxonomy by Michael Howlett and Benjamin Cashore (hereafter H\&C) gives six dimensions of policy change and offers the potential for a new understanding of developments in the CAP that Hall cannot account

1. For example B. HOGWOOD, L. GUNN, Policy Analysis for the Real World, Oxford University Press, Oxford, 1984. See also H. HECLO, Modern Social Politics in Britain and Sweden, Yale University Press, New Haven CT, 1974.

2. P.A. HALL, Policy Paradigms, Social Learning and the State, in: Comparative Politics, 25(1993), pp.275-296. 
for. ${ }^{3}$ The present paper, first, discusses the $\mathrm{H} \& \mathrm{C}$ framework in terms of identifying patterns of CAP change across time. The significance of the analytical problem of specifying the CAP over time is manifest in the substantial variation in accounts of CAP reform over the last twenty years, from those who see strong continuity in the CAP as reform is dominated by budget and trade interests; to those - as in Elton's paper in this volume - who see a new paradigm in the CAP in which environmental, developmental and animal welfare interests are to the fore. The main section presents a historical perspective on the reform of the CAP using the $\mathrm{H} \& \mathrm{C}$ framework, in which we eschew paradigm-spotting for a richer, more nuanced account of CAP reforms on different dimensions; and we avoid the a priori presumption that there are one-off paradigmatic episodes of CAP reform that fundamentally shift its trajectory.

\section{Specifying CAP change}

$\mathrm{H} \& \mathrm{C}$ argue that the orthodoxy in the social science study of policy change is the punctuated equilibrium pattern, where rare paradigm change punctuates long periods of incremental adjustments due to shocks induced by institutional change or new actors, ideas, beliefs which are exogenous to the policy system. They see this orthodoxy as a synthesis of earlier work on incrementalism and on policy paradigms. ${ }^{4}$

However, logically prior to any tracing of policy change over time is the problem of defining a policy. Of Hall's three orders, orders one and two (the choice of policy instruments and their settings) are endogenous to the policy subsystem and incremental, but third order paradigmatic change is exogenous. Hall makes a further distinction between theoretical or ideational change in policy (third level) and concrete, action based and/or on-the-ground policy change which occurs at the first and second levels of policy change.

H\&C suggest that the popularity of Hall's framework has limited theoretical and empirical progress in policy studies. They also start with the identification of three levels of policy: the theoretical abstract level of the composite whole e.g. trade policy; the programme level e.g. tariffs; and the on-the-ground level e.g. setting the appropriate tariff rate. In a novel step, policy ends are separated from policy means for each of those levels. Thus we have six dimensions on which policy might be measured and change identified (in order of decreasing abstraction): ${ }^{5}$

3. M. HOWLETT, B. CASHORE, Re-Visiting the New Orthodoxy of Policy Dynamics: The Dependent Variable and Re-Aggregation Problems in the Study of Policy Change, in: Canadian Political Science Review, 1(2007), pp.50-62.

4. C.E. LINDBLOM, The science of muddling through, in: Public Administration Review, 1(1959), pp. 77-88; C.E. LINDBLOM, Still muddling, not yet through, in: Public Administration Review, 39(1979), pp.517-526. See also P.A. HALL, op.cit.

5. M. HOWLETT, B. CASHORE, op.cit., p.55. 
- Policy ends: (iii) Goals, (ii) Objectives, (i) Settings.

- Policy means: (iii) Instrument logic (general regulatory preferences/strategies), (ii) Mechanisms/instruments, (i) Calibration of those instruments.

At the highest, most abstract level, ends iii, goals, refer to the broad types of idea that shape policy. Means iii instrument logic, meanwhile, refers to the broadest notions of preferences that policy implementation should reflect. At the intermediate Programme Level, policy objectives, ends ii, identify what the policy formally should target, whilst means ii, mechanisms, identify the particular instruments, literally, to be used to those ends. Third, there are the on-the-ground measures. Ends i, settings, refers to the specific requirements of policy; whilst means i, calibrations, specify the ways in which the instruments are to be used. Level i probably leads to the most confusion, given that the word 'settings' in general usage addresses what $\mathrm{H} \& \mathrm{C}$ call calibration, whilst Hall's use of the term conflates H\&C's notions of settings and calibration. Another possible confusion is ends ii, objectives, given this term is also used to describe the statements in the Treaty of Rome which set out the 'objectives' of the CAP. In the present paper, all terms are used in the H\&C sense.

The strength of the work of H\&C is to point the field of policy studies beyond the strict dualism that has provoked most criticisms of Hall: that policy change is either incremental or big bang, paradigmatic, with nothing in between. What $\mathrm{H} \& \mathrm{C}$ offer is a more sophisticated view of the different constituent elements of policy or combinations of the constituent elements, and in doing so they reveal potential and actual patterns of policy change obscured in the Hall framework. In particular, they give an analytical edge to the intuitive insight of many CAP scholars regarding the potential for incremental but cumulative change i.e. that small adjustments in the same direction can profoundly shift policy over time in the absence of large exogenous shocks.

Despite the advance made by $\mathrm{H} \& \mathrm{C}$, we are still left with the question: what is the relationship between different policy levels? There is no impeccable formal logic to the relationship. One response is to deny any relationship or connection between goals or instrument logic at the abstract level of the policy 'whole' (ends iii or means iii, respectively) and the actual setting of CAP instruments. Instead, each level is described and explained separately. Following this approach, within the field of policy studies different descriptions, metaphors, concepts, models and theories used in analysis belong to different levels; and the requirement for scholars is to be explicit about the dualism or trialism implicit in their analysis.

Whatever the appeal of this answer in terms of academic neatness, however, almost all CAP scholars assert a link between different levels and regard this link as at the crux of their subject. For example, Elton in this volume argues that change at the broadest level of goals and instrument logic - in his terms, and following Hall, the policy paradigm - is a necessary precondition for change in instruments and their settings. Because we construct the CAP as a dependent variable, any claim that there is a relationship between different policy levels involves constitutive rather than causal reasoning: scholars are looking at the structures and their levels that constitute policy rather than investigating the set of conditions that might cause policy and 
policy change. Policy can be constituted internally in a form of reductionism; in an analogy with the natural sciences, policy has a genetic structure. This view in broad terms underpins methodological individualism in the social sciences. An entity has an internal structure which accounts for its properties. On a strict reductionist view, the policy whole is nothing but its internal constitutive elements. In addition, entities can be constituted externally as a holistic entity by reference to external structures in which they are embedded. On this view, policy is constituted as a whole with reference to entities such as government departments, legislatures, think tanks and so on. This external constitution is characteristic of the literature on the comparative political economy of public policy, where change is explained, for example, in terms of the differential effects of societal institutions, variations in national 'styles' of capitalism or the uneven consequences of globalisation for different welfare state types.

What are the consequences of these two types of constitutive reasoning for the analysis of the CAP? Once scholars accept that the CAP is to some degree externally constituted they commit themselves to some form of structuralism where the structure of the whole in some way governs its constitutive elements. This is the case because without structures at the level of the whole, the properties of the whole (any regularities and so on) would not exist: they would be nothing but the constituent elements i.e. you would have reduced the CAP to its constituents.

In practice, we think the literature should develop the general acknowledgment that the CAP is a social construction and draw the implication that its analysis needs to be synthetic; that is, it must be simultaneously holistic and reductionist. The field must leave open, but central, the thorny level of explaining relationships between levels in the CAP. Unlike holism that stays at the top and reductionism that sticks to the bottom, synthetic analysis of the CAP takes a round trip from the top to the bottom and back. It encompasses two or more perspectives, looking at the CAP whole on its own level and looking at it on the levels of its constituents. To connect the different levels, it employs two kinds of explanations: macroexplanations and microexplanations.

Macroexplanations develop scientific concepts and theories for composite variables without mentioning their constituents. They delineate properties for the policy whole, represent them on dimensions, and find the causal regularities and mechanisms among them. Macroexplanations constitute the primary explanatory level of systems thinking, and they enjoy a high degree of autonomy. In these terms, it makes sense to say that 'agricultural policy is changing because' or 'the CAP has tended in this direction because' and so on. This is the level at which many debates about the role of ideas in the CAP over time take place. For example, it has been argued that despite shifts in the ideational underpinnings of the World Trade Organisation (WTO) rules on international agricultural trade, the CAP remains governed by a state-assisted policy paradigm, in which agriculture remains an exceptional sector of the economy which for reasons of history, politics and culture is not the subject of standard market 
governance. ${ }^{6}$ However, for a full understanding of the systems including their composition, such macroexplanations are necessary but not sufficient. For this we also need microexplanations that connect the properties delineated in macroexplanations to the properties of the constituents: microexplanation depends on macroexplanation, which first sets out what needs microexplanation.

Microexplanations introduce their own concepts, theories and assumptions that are not found at the top level. Such extra theorising ensures the irreducibility of the whole into its parts. Microexplanations explain system properties without explaining them away, as reductionism does. They not only find the micromechanisms underlying macroscopic properties, but also explain, for example, how structures of abstract ideas at the policy system level of the CAP constrain the behaviours of individual constituents in making detailed, day-to-day CAP policy. They look at the whole causal structure spanning the system and constituents from all angles - upward causation, downward causation - to get a comprehensive grasp of the complexity of composition. In short, the appropriate approach to the composition problem is not to reduce the policy description framework but expand it to accommodate more perspectives, more postulates, and more theoretical tools to filter out irrelevant microscopic details and define novel emergent macroscopic properties. A multiplicity of approaches and models is a characteristic of all social sciences that wrestle with complex phenomena and should be welcomed and encouraged in the study of public policy.

A composition problem arises for the CAP using the $\mathrm{H} \& \mathrm{C}$ framework: it is more complex than implied by the notion of a single holistic entity. There are different types and degrees of change and thus, at the micro level, change and stability may coexist. If we adopt the analytical strategy of describing the CAP at the micro or finegrained level in terms of constituent elements - as a complex matrix of multiple policy instruments rather than as a single, composite variable - then different explanatory strategies can be adopted.

A first alternative line of argument to the macro/holistic approach is to view policy change as continual, but generally incremental and gradual. Focusing on specific elements rather than the policy system as a whole, we may observe changes in terms of instruments, but this has more frequently involved re-setting existing policy instruments than introducing new ones. It is generally ineffective in terms of ameliorating longer term, structural pressures for reform and much remains in place through reform episodes from previous policy regimes. Recent writings in the historical institutional school have heralded a return to an older tradition of incrementalism in policy processes, represented most clearly by the works of Charles E. Lindblom over many decades. ${ }^{7}$ Institutions are adapted to new circumstances through a process of

6. C. DAUGBJERG, A. SWINBANK, Ideas, Institutions and Trade: The WTO and the Curious Role of EU Farm Policy in Trade Liberalisation, Oxford University Press, Oxford, 2009.

7. K. THELEN, Time and temporality in the analysis of institutional evolution and change, in: Studies in American Political Development, 14(2000), pp.102-109; K. THELEN, How institutions evolve, in: J. MAHONEY, D. RUESCHMEYER (eds.), Comparative Historical Analysis in the Social Sciences, Cambridge University Press, Cambridge, 2003, pp.208-240; W. STREECK, K. THELEN 
incremental adjustment rather than through periods of drastic and rapid change, achieved by means such as layering, conversion and drift: "The picture of institutional evolution that emerges from these analyses is one in which it is not so useful to draw a sharp line between cases of institutional stability versus change". 8

Once policy change is acknowledged as more nuanced for analytical purposes than this duality, we return to the problem of composition. The central thrust of both Hall and $\mathrm{H} \& \mathrm{C}$ is that policy must be understood at different levels. By combining microexplanations with macroexplanations, in the context of the multiple policy dimensions offered by $\mathrm{H} \& \mathrm{C}$, we may observe a policy simultaneously exhibiting elements of both continuity and change. As we set out in the next section, change with the CAP comes when policy reproduction mechanisms are upset or disrupted, usually brought about through either the budget (endogenous shock) or trade (exogenous shock), although environmental concerns and food safety pressures have also had some, albeit limited, effect in disrupting the reproduction of CAP mechanisms. As a result, the question of what it is about policy that is path dependent does not admit a single, conclusive answer; rather it remains an open and empirical matter, to be explored in the context of particular policies, each with their own specific composition and structure.

This fine-grained analysis refines what can be meant by reform. The macro perspective can identify a critical juncture faced by a (complex) policy, which can lead to individual institutions being changed, removed or introduced ('layered-in'). ${ }^{9}$ The CAP consists of multiple institutions, commodities and countries, so 'CAP reform' may involve amendments to only some of its individual institutions. A common view on types of change contrasts incremental policy changes and "the policy feedback literature rooted in historical institutionalism, [the latter viewing] change not as an incremental process but as a rather dramatic one". ${ }^{10}$ The fine-grained approach adopted in this paper allows for a perspective on change contra Carsten Daugbjerg, that accommodates and explains the incremental accumulation of pressure for change, the upsetting of institutional reproduction and gradual adaptation of policies and institutions.

By framing the CAP as a nexus of inter-related institutions distinguishable using the policy dimensions of $\mathrm{H} \& \mathrm{C}$, the present analysis ultimately can deepen our understanding of the nature of the CAP reform over time, showing how stasis and change can co-exist in the CAP, combining microexplanations and macroexplanations and thus distinguishing individual institutions from the overall institutional matrix. As a final thought in this section, it should be noted that this analytical approach does not close off additional scholarly contributions. Thus one may extend a familiar saying

(eds.), Beyond Continuity: Institutional Change in Advanced Political Economies, Oxford University Press, Oxford, 2005.

8. K. THELEN, Time and temporality ..., op.cit., p.106.

9. Synonyms can include 'policy framework', 'institutional matrix' or 'nexus of institutions'.

10. C. DAUGBJERG, Policy Feedback and Paradigm Shift in EU Agricultural Policy: the effects of the MacSharry reform on future reform, in: Journal of European Public Policy, 10(2003), pp. 421-437, p.423. 
by noting that if macroexplanations address the wood or forest, and microexplanations examine the trees, there is still much to be added by exploring specific areas of undergrowth, through detailed archival analysis of the sort undertaken by several contributors to the Special Edition.

\section{Tracking the CAP Through Time}

Article 39 of the Treaty of Rome identified five objectives for the CAP. The details of policy - especially how to achieve the objective of ensuring a fair standard of living for the agricultural community - were then established over the following decade. It is beyond the scope of the present paper to analyse this in detail, but some aspects need highlighting. ${ }^{11}$ When the CAP was established, a wide range of instruments were adopted across commodity regimes, but the principal policy adopted was price support. ${ }^{12}$ Several factors help explain this. First, several countries employed price support previously. An analysis of this continuity is beyond the scope of the present paper but Carine Germond, in this issue, explores in-depth for France and Germany the difficult transition from national to common policies. Second, there was widespread political opposition to direct payments, seen as a social handout. Third, direct payments would have had a much larger impact on the emergent EU budget whilst the prevailing farm structure, with millions of small farms, would have raised administration costs substantially. ${ }^{13}$

The choice of price support created a particular dynamic for CAP spending. By linking ('coupling') production and support levels, it stimulated production and thus drove up CAP spending. This increase at the aggregate level of total CAP spending was driven by spending on commodities for which production exceeded EU consumption: that is, commodities that were in surplus. This was because the principal expenditures under price support were linked to the maintenance of high prices and thus the removal of surpluses from the internal market that could undermine them: the cost of intervention storage and refunds or subsidies on exports to third countries.

Initially, the EU budget represented a positive sum game - as total spending on the CAP rose, every country and producers therein could receive more CAP transfers: the member states, individually and collectively, had no budgetary incentive to reform the CAP. Reform events imply that, eventually, the policy reached a critical juncture. Initially the principal reason was budgetary - but defined at the level of the total EU budget, upon which the member states, through the Treaty of Rome, had imposed a

11. See, inter alia, E. NEVILLE-ROLFE, The Politics of Agriculture in the European Community, Policy Studies Institute, London, 1984; R.W. ACKRILL, The Common Agricultural Policy, Sheffield Academic Press, for the University Association for Contemporary European Studies, Sheffield, 2000.

12. R.W. ACKRILL, op.cit., pp.44-45.

13. Katja Seidel, in this volume, explores further the largely unsuccessful Community attempts to improve the economic efficiency of the structure of farming in the early years of the CAP. 
Balanced Budget Rule (BBR). Spending could not exceed a certain level, defined in terms of total revenues that could be collected in that year. This represented a domain constraint on decision-making, affecting "the permissible outcomes of solutions that may be allowed under any agreed-on procedures". ${ }^{14}$ It can also be thought of as a static constraint, a ceiling on spending that is fixed annually and can be changed only in accordance with pre-determined procedures.

Introduced into the Treaty of Rome in 1970 is a distinction between Compulsory Expenditure (CE) and Non-Compulsory Expenditure (NCE), a procedural constraint affecting the rules for collective decisions. ${ }^{15}$ The key feature of this distinction for current purposes is that NCE levels are determined directly whereas, with CE, once the expenditure-generating policy instruments are in place, spending levels cannot then be controlled directly, but only through changes to those policy instruments ('policy reform'). Price support created an ongoing production incentive which generated growing surpluses and thus ever-higher CAP spending. CE, a dynamic procedural constraint was, ultimately, to conflict with a static domain constraint, the BBR.

This offers one of the principal macroscopic explanations of CAP reform: regardless of the level of spending on individual commodities - and of the response in terms of which commodities are involved in a reform of CAP instruments - of concern is the level of spending at the macro 'CAP' level. What our synthetic analysis below does, however, is analyse also the response to such a macro pressure at the microscopic level of individual components of the dependent variable. By the late 1980s, budget pressures had not gone away entirely but were now joined and, to a considerable extent, overtaken as a point of focus by concerns over the extent to which agricultural policy instruments distorted trade - again, a key macroscopic pressure, but which yielded reform responses at the microscopic policy level. From this time also, as analysed by Elton in this volume, concerns were growing about the wider policy impacts of agricultural support policies: on the environment, the safety of food, plant and animal welfare, and so on, factors also addressed in the analysis below.

What will be clear from the following discussion is that the very phrase "CAP reform' is ambiguous: the CAP covers many different commodities and utilises many different types of policy instruments to achieve different policy goals. To aid this discussion, in analysing CAP reforms we shall identify macro-level reform pressures on 'the CAP', and analyse the policy responses with reference to the six elements of the H\&C framework introduced earlier: ends iii (goals), ends ii (objectives), ends i (settings), means iii (instrument logic), means ii (mechanisms or instruments), and means i (instrument calibration). Level iii in each case is the most theoretical abstract level of the composite whole; level i on-the-ground.

14. J.M. BUCHANAN, R.A. MUSGRAVE, Public Finance and Public Choice: Two Contrasting Visions of the State, MIT Press, Cambridge MA, 1999, p.118.

15. Ibid. 


\section{CAP Reform - Changing Policy Means or Ends?}

For many years, not only did price support dominate CAP policy instruments, but there was an annual process of fixing support prices for the coming year. This process represented an annual means i re-calibration of key policy instruments, but not in a way that constituted policy reform. Early attempts at reform, therefore, involved not only means i recalibration of support price levels but also, as a minimum, means ii changes whereby instruments were introduced that affected prices in a different way. Moreover, reforms prior to 1984 and the breaching of the BBR were still being negotiated in an environment of a positive-sum budget game. There was a trade-off between price cuts to try to limit the production incentives which were driving spending upwards, but which would also undermine the principal policy goal (ends iii) of supporting farmers' incomes. In practice the former lost out and the means i changes that were agreed were minimal in extent. The first two CAP reform episodes considered here, the dairy co-responsibility levy (CRL) introduced in 1977 and Guarantee Thresholds agreed in 1982, both conform to this characterisation of new means ii instruments introduced to effect means i price changes in some pre-determined way. ${ }^{16}$

The principle underpinning the co-responsibility levy was that producers should share the financial burden of dealing with the surpluses they were producing. The resulting levy on producers, set as a small (no more than $3 \%$ ) share of support prices, represented an implicit but de facto downwards re-calibration of support prices. Subsequently, however, it was shown that there was an offsetting increase in support prices agreed in the annual rounds of price-fixing, despite the small impact overall of the CRL (EU prices were routinely $40-60 \%$ above world price levels). ${ }^{17}$ Producers were thus unaffected by the net means i changes - but consumers were worse off because the rise in prices increased still further the production incentives to producers in the sector, dairy, that was already the most expensive for the EU budget. Note that the CRL introduced into the cereals sector in 1986 shared all key features with the dairy CRL other than it was not preceded by agreement of a 'normal' price rise. Even so, the magnitude of re-calibration (means i) remained modest.

Whilst the dairy sector had been in surplus since the 1960s, in the late 1970s it was joined by other key sectors, notably beef and cereals (that were also, not coincidentally, underpinned by price support). High world commodity prices at the turn of the decade reduced the unit export refunds payable on the rising volume of subsidised exports sufficient to see a brief dip in CAP spending; but very soon rising spending in several sectors combined to threaten the BBR, as higher CAP outlays drove up total EU spending. The first multi-commodity reform attempt, agreed in 1982 before the BBR was breached, introduced another new means ii policy instrument, Guarantee Thresholds. Not for the only time was a CAP reform misleadingly named. Guarantee Thresholds worked by triggering negotiations on price cuts should

16. See R.W. ACKRILL, op.cit., p.63, for more discussion of various CAP reforms.

17. L. HUBBARD, The Co-Responsibility Levy: A Misnomer?, in: Food Policy, 11(1986), pp.197-201. 
a certain production level be exceeded. That said, even production above the Threshold received full support, whilst the price cut was introduced only after a 'normal' price rise had been agreed through the annual price-fixing. As with the dairy CRL before it, therefore, the net re-calibration of policy instruments was minimal and, in some cases, support prices still rose.

Although the 1977 and 1982 reforms saw a change at the level of means ii, their design and implementation were consistent with the extant means iii of price support; nor were any policy ends altered. Does this mean, therefore, that for a CAP reform to change means iii and/or policy ends, a macroscopic pressure is needed? The first time this is seen is in 1984, when production quotas were imposed on dairy farmers. ${ }^{18}$ Quotas operated via instruments layered-in as a means ii change that were, in their basic design, very similar to Guarantee Thresholds. The key difference was that with dairy quotas, if production exceeded a specified level the penalty would be a 'superlevy' that, depending on the exact instruments a member state could adopt, would be either $75 \%$ or $100 \%$ of the support price. This imposed a limit on the level of production eligible for support, the first time CAP support for any commodity ceased to be 'open-ended'. As such, this was the first reform when a policy end was changed: specifically a policy setting (ends i).

Why, though, was this reform of the dairy sector, which drew on very similar means ii instruments, implemented in a way so fundamentally different to the 1982 reform? Moreover, since the dairy sector had been in surplus since the 1960s and was by far the most expensive element of the EU budget as a result, why was it reformed only in 1984? The answer lies with the situation of the EU budget overall: it was in 1984 that the BBR was breached. ${ }^{19}$ This macro pressure affected the CAP directly, because it was CAP spending that pushed total EU spending up to and through the revenue ceiling. The (microscopic) focus in the reform on the dairy sector is explained by the fact that by the early-mid 1980s, it took one-third of total CAP spending and one-quarter of the entire EU budget. As a result the macro-level problems caused by CAP spending were, at this stage, both caused by and could be addressed through reform of instruments in this single sector.

The macroscopic perspective also enables other changes to the institutions of the EU budget to be identified that, because agricultural and budgetary institutions occupy common space, affected the CAP. In response to the budget crisis, a new budgetary objective of Budgetary Discipline sought to contain EU spending. Part of this, the Agricultural Guideline, addressed aggregate CAP spending. The Guideline set a limit on the rate of increase of EU budget revenues, so that CAP spending should cease to grow as a share of total EU spending. This therefore represented a new ends

18. For a detailed analysis see, notably, M. PETIT, M. DE BENEDICTIS, D. BRITTON, M. DE GROOT, W. HENRICHSMEYER, F. LECHI, Agricultural Policy Formation in the European Community: The Birth of Milk Quotas and CAP Reform (Developments in Agricultural Economics 4), Elsevier, Amsterdam, 1987. Note that Guarantee Thresholds were extended in 1984, to cover durum wheat, dried grapes and sunflower seed.

19. Strictly speaking the BBR was breached in 1983. Problems were put off until 1984, however, by carrying over the unfunded portion of EU spending to 1984. 
ii objective for the CAP. The problem was that it was not accompanied by any new instruments (means ii) to enforce it.

1984 saw the dairy sector reformed, with changes to policy ends addressing the perpetual growth in spending. A lack of change in the policy ends of other commodities, however, meant that spending on, in particular, cereals and beef, continued to grow, driving overall CAP spending upwards (between 1980 and 1990 nominal CAP spending roughly doubled, during which time the share going to the dairy regime roughly halved, to about $20 \%$ ). A decision in 1986 to increase the budget revenues available, via the VAT-based own resource, meant that when a package of reform measures to both the CAP ('stabilisers') and budget was negotiated in 1988, the (macroscopic) budget pressure on the CAP was no longer binding.

The multi-commodity 'stabiliser' CAP reform was, at the level of policy means, similar to the Guarantee Thresholds of 1982, with a cut in support prices of up to $3 \%$ triggered by production exceeding a certain level - the 'Maximum Guaranteed Quantity'. That said - and reflecting the difference between the 1986 cereals CRL and the 1977 dairy described earlier - the stabiliser reform did not start with a 'normal' price rise (a parallel which, of itself, reflects a shift in means iii). Moreover, the price cut would not be negotiated but would be automatic if production exceeded a certain level; also a change in means iii, as the new instrument logic this represented reflected changed regulatory preferences. On the other hand, just as the notion of a Guarantee Threshold was a misnomer, so too was 'Maximum Guarantee Quantity': as with the earlier case, all production was supported in full. As a result of this, ends i remained unchanged. Furthermore, even though the automatic price cut and the CRL were additive, resulting in a price cut of up to $4.5 \%$, the net effect was still marginal in relation to the prevailing world-EU price gap (the changes at means $\mathrm{i}$ level, the recalibration of support price levels, remained modest). ${ }^{20}$

It is worth noting that the original Stabilisers proposal had a trigger based directly on spending, rather than indirectly via production, but this proved unacceptable politically. Even though, since 1984, the EU budget represented a zero-sum game, spending could still rise in absolute terms. The implicit ceiling on spending embedded in this proposal would have represented a change to policy ends $i$, that the member states were not ready to make. That said, as part of Commission President Jacques Delors' vision for a restructuring of EU spending, changes were made to the wider institutions of the EU budget. Of direct relevance for the CAP, the Agricultural Guideline was strengthened in that the growth rate of CAP spending should be contained to $74 \%$ of the growth rate of available resources, but again this overlapping budgetary end was not matched by new effective policy means of delivery. ${ }^{21}$

20. For more on stabilisers see W. MOYER, T.E. JOSLING, Agricultural Policy Reform: Politics and Process in the EC and USA, Harvester Wheatsheaf, Hemel Hempstead, 1990.

21. The budget changes are analysed in R.W. ACKRILL, A. KAY, Historical Institutionalist Perspectives on the Development of the EU Budget System, in: Journal of European Public Policy, 13(2006), pp.113-133. 


\section{The 1992 CAP Reform}

The combination of reformed budgetary institutions, but CAP changes that introduced new ends without matching means would, by 1992, see 'macro' budget pressures once again affecting the CAP as the BBR was once again threatened. By 1992, however, a second macro factor (this time exogenous to the EU) was putting pressure on the CAP - the trade talks in the General Agreement on Tariffs and Trade (GATT) Uruguay Round..$^{22}$ The foregoing discussion raises a crucial question - what microscopic reforms could put the CAP as a whole on a new trajectory, ensuring consistency between CAP and budget institutions and between the CAP and trade concerns? Several authors argue the 1992 reform reflects principally either budget or trade factors. ${ }^{23}$ The present paper, however, argues it was a confluence of the two - although, as in 1984, the resulting reform focused only on some commodities. In identifying these reform pressures, other factors are not denied. Growing concerns over food safety, animal welfare and the environment all helped shape policy, but the demands of budgetary and trade factors defined the limits of feasible policy responses. The factors identified by Elton in this volume as emerging in the CAP in the late 1980s were, we would therefore argue, not as influential in 1992 as on subsequent reforms - as explored below.

The combination of budget and trade pressures is significant because whilst the EU could leave ends iii goals largely unchanged, the GATT talks challenged policy ends ii, objectives. Specifically, on domestic support aggregate budgetary transfers could be maintained if they were channelled through mechanisms that distorted trade less, a change to means iii. In effect, ends iii were left unchanged, through an acceptance by the EU of an ends ii change. This was combined with returning budget pressures that once again challenged policy ends i. The GATT talks, by creating a shift in EU regulatory preferences towards more de-coupled support also, therefore, resulted in a change in means ii, as new instruments consistent with this means iii change were introduced. A key point to note from this is that whilst $\mathrm{H} \& \mathrm{C}$ identify six separate policy elements, this is a useful heuristic but those elements are by no means mutually exclusive and, in some cases, could be seen as joint elements in practical terms.

The GATT talks also confronted other elements of the CAP, in particular price support as the most trade distorting of policies. As noted above, spending could be maintained in aggregate, so long as it was channelled through less trade-distorting instruments. As a result, the instruments of price support remained, but means i recalibration of a sufficient degree was undertaken to ensure spending on trade distorting policy instruments fell by enough to permit a multilateral agreement on domestic agricultural support. The new instruments introduced were sufficiently de-

22. For analyses of CAP-GATT linkages, see A. KAY, The Reform of the Common Agricultural Policy: The Case of the MacSharry reforms, CAB International, Wallingford, 1998; R.W. ACKRILL, op.cit.

23. See A. SWINBANK, C. DAUGBJERG, The 2003 CAP Reform: Accommodating WTO Pressures, in: Comparative European Politics, 4(2006), pp.47-64. 
coupled to ensure they were agreeable to other members of the GATT. Their calibration meant, moreover, that financial transfers made through them to EU farmers obtained political support within the EU. Whilst the extent of re-calibration of individual instruments was considerable, the net effect across all instruments for a particular commodity regime was much more modest. ${ }^{24}$

The means i changes to price support instruments, moreover, were sufficient to ensure that the resulting reduction in export subsidisation ensured agreement on that element of the GATT talks. The third part of the agriculture talks in the GATT, over market access, in essence, required imports to rise. This, in principle, represented one of the few challenges to ends iii, as it questioned the principle of Community Preference, a foundational feature of the CAP that established trade barriers protecting relatively inefficient EC producers from lower cost imports. That said, by reducing external barriers (the threshold price) by less than internal support prices, Community Preference was not only retained but, by this definition, increased (although the analysis of Mark Spoerer, in this volume, finds that by a range of other measures the protection the CAP afforded producers was starting to decline by the late 1980s). As a result, this ends iii Goal of the CAP may have been challenged, but ultimately was left intact.

It is worth noting that the 1992 reform focused primarily on the cereals complex (cereals, oilseeds and livestock, especially beef), commodities supported by the most trade distorting policy instruments, those of price support; and which were the most expensive, the direct link between price support and budget outlays having been discussed earlier. ${ }^{25}$ It is also worth reiterating the macroscopic nature of the budget and trade pressures. Thus the extent of the means ii and means i changes to the commodities of the cereals complex meant agreement could be reached in the GATT talks with much more modest changes to other commodities such as sugar and dairy.

Two further features of the direct payments saw changes to the budgetary aspects of ends i, policy settings. The value of each unit payment was fixed; and the total number of payments that could be made (per hectare for arable, per animal for beef) were limited. Thus the total possible cost of these payments had an in-built ceiling. Although the introduction of the payments saw a one-off jump in budget costs for the commodities concerned, once phased-in the trajectory of CAP spending was much flatter. This provided a long-term solution to the budget concerns surrounding the CAP. Moreover, these features of the direct payments can also be seen as a radical

24. See also R. ACKRILL, R.C. HINE, A.J. RAYNER, M. SUARDI, Member States and the Preferential Trade and Budget Effects of the 1992 CAP Reform: A Note, in: Journal of Agricultural Economics, 48(1997), pp.93-100.

25. Beyond the cereals complex, price support was still used to support dairy and sugar production. In the former case, quotas limited production and thus exportable surpluses and budget costs. With sugar, production was limited by quotas, whilst a levy on producers covered the budget costs of the domestic policy regime. The latter regime was reformed in 2005/06, with support prices and quota levels cut significantly: R. ACKRILL, A. KAY, Multiple streams in EU policy-making: the case of the 2005 sugar reform, in: Journal of European Public Policy, forthcoming. 
change in means iii, instrument logic. The CE/NCE distinction still existed, but the in-built spending limit controlled CE endogenously.

Thus whilst the 1992 reform did not succeed in changing ends iii, policy goals, the combination of endogenous and exogenous macro pressures (respectively, budget and trade concerns), yielded changes to ends ii and i; and all three levels of policy means. That said, with the unit value of the new direct payments determined with direct reference to the extent of the re-calibration of support prices, those who benefited most under price support continued to benefit most under the new post-1992 payments. On this point, therefore, we would challenge the conclusion of one recent contribution to the literature on CAP reform and CAP policy instruments, where it is claimed that "the policy instrument [of price support] lost legitimacy because it was simply not efficacious". ${ }^{26}$ The direct payments introduced in 1992 actually cemented the unequal distribution of financial transfers to farmers, the reform being motivated by concerns unrelated to the efficacy of price support as a means of providing income support to farmers. Indeed, to this day the issue of farm incomes has never adequately been addressed. ${ }^{27}$

\section{Reforms since 1992}

The negotiations that resulted in the 1999 reform began with the publication, in 1997, of the 'Agenda 2000' programme. This included the Financial Perspective for 2000-2006 and reforms to the regional and agricultural policies, preparing the EU for what would become the 2004 and 2007 enlargements. Again, budget and trade concerns were present. The principal budget concern was being able to afford the CAP in an enlarged EU, respecting the budget limit negotiated separately within Agenda 2000. This task was made harder by the 15 member states agreeing to keep total EU spending unchanged post-enlargement as a percentage of Gross National Product (GNP), even as the size of the possible enlargement rose from six countries to ten during the accession negotiations. Trade pressures arose as a result of the imminent resumption of trade liberalisation talks in agriculture, under what would become the WTO Doha Round. These would challenge not only the remaining price support but also any support that was not fully de-coupled - including the direct payments agreed in 1992.

The 1999 CAP reform reached by the European Council at the end of March 1999, addressed two distinct elements. The first continued the changes begun in 1992, with further cuts in support prices and (partly) offsetting increases in direct payments. In this element of the reform, therefore, no new instruments were introduced but existing

26. W. GRANT, Policy Instruments in the Common Agricultural Policy, in: West European Politics, 33(2010), pp.22-38.

27. B. HILL, Some Economics of Public Statistics, in: Journal of Agricultural Economics, 59(2008), pp.387-420. 
instruments were recalibrated (means i). At the aggregate level of total CAP spending, however, this represented a further shift in CAP spending from coupled to de-coupled support instruments, from price support to direct payments. This reinforced the ends ii and means iii changes introduced in 1992.

The original reform agreement, reached by the Council of Agriculture Ministers in mid-March, saw a deeper price cut and larger compensating rise in direct payments. When the European Council met two weeks later, however, they altered the extent of the means i recalibrations, by reducing both the depth of the price and the rise in direct payments, in order to reduce the overall cost of the reform to the EU Budget and ensure it respected the overall budget limit determined by the European Council a month earlier. ${ }^{28}$ In this case, therefore, the macro budget pressure, working through the ends ii policy of Budgetary Discipline, acted to limit the means i recalibration of CAP support instruments. This can also be seen as an ends i change, as means $i$ changes were made to respect a new desired level of budget spending at the macro level of the CAP.

The second element of the CAP reform brought together several existing and new non-income support measures under the heading "rural development", also known as Pillar II of the CAP (Pillar I being income support). These measures covered a wide range of policy issues, including agri-environmental concerns and elements directed at the wider rural economy rather than the agricultural sector per se. As such, this reform represented a change to ends iii, not by changing what was there already but by layering-in new goals for the CAP. This also manifested itself through the introduction of specific new ends ii objectives and means ii instruments, notably with several rural development instruments being more fully decoupled than the Pillar I payments at the time. Furthermore, elements of rural development, plus 'cross-compliance' conditions for the receipt of direct payments, brought environmental concerns more directly and explicitly into the CAP. The introduction of the rural development policy measures also brought about a means iii change to instrument logic: for the first time CAP measures were not $100 \%$ funded from the EU budget but were co-funded by the member states. A further means ii change was brought about through 'modulation', whereby member states could choose to take some of the money allocated to direct payments and recycle it into additional rural development funding - and option that would manifest itself through further instrument re-calibrations.

Thus the first part of the 1999 reform developed the higher level (ends ii and means iii) changes of 1992, but itself only involved means i changes. Indeed, it is a paradox of the 1999 reform that the macro budget pressure limited the extent of the instrument recalibration. The second part of the CAP reform package, however, saw much more profound changes, even seeing new ends iii goals layered into the policy mix. The 1999 reform also reveals a weakness with the H\&C classification. The changes made in the second part of the CAP reform changed even ends iii, yet most money continued to be channelled to farmers, through Pillar I instruments largely unchanged from 1992

28. See R.W. ACKRILL, op.cit., pp.116-127 for a detailed analysis of this sequence of events. 
other than through some re-calibration. Thus questions remain over how or even if the different elements of the H\&C framework can be valued and ranked in assessing the extent of a reform overall.

It is with this in mind that we turn to the next multi-commodity reform of the CAP. The 1999 agreement required a 'mid-term' policy review in 2002. With WTO talks focusing attention on the remaining trade distortion within the CAP, Commissioner Franz Fischler assembled a reform package, agreed in 2003, that addressed at least some trade concerns. Most CAP institutions were left unaltered, but two changes of note were made. First the reform introduced a cross-commodity Single Farm Payment (SFP) to replace existing direct payments, primarily those within the cereals complex. Payments would be based on past transfers with no specific requirements concerning current production. The intention was to de-couple payments sufficiently to assure protection from future cuts in coupled support agreed through the WTO talks, although the final agreement did permit member states to retain some post-1992 payments. ${ }^{29}$ This element of the 2003 reform is thus unique in CAP history, as it involved a change to means ii that was not accompanied by a means i re-calibration (although the changes to modulation, discussed below, did re-calibrate support instruments). This feature of the 2003 reform does not, of itself, represent an ends i change, but is strong confirmation of the ends i change made in 1999 (which was, in turn, a reinforcement of the ends i change made in 1992). The remaining institutions of price support were left untouched, although the subsequent sugar reform of February 2006 included a $36 \%$ price cut.

The 2003 reform also enhanced the environmental institutions of the policy. Eligibility for the SFP requires compliance with several environmental conditions, whilst modulation of SFP monies into rural development is now compulsory and the ceiling on transfers raised - a combination of adapting means ii and a change in means i. Whilst the institutions associated with post-1992 direct payments were not removed from the CAP matrix, most budget transfers would now be channelled through the new institutions of the SFP. This layering-in of new support instruments means, however, four sets of income-support institutions exist alongside each other (price support, post-1992 direct payments, post-2003 Single Farm Payments; and Rural Development), with each in turn receiving greater shares of CAP spending as they are introduced to supersede more problematic institutions. ${ }^{30}$ The shift to fully decoupled direct payments is a further change in ends ii. Decoupling also changes means iii because of a change, indeed a reversal, in instrument logic: instead of making transfers to farmers based on what they produce, a transfer is now made in the form of the SFP, with farmers free to choose what they will do.

The latest reform - the Health Check - continues to nudge the CAP in a certain direction, reinforcing earlier reforms. Many of the key elements, though (for example

29. See also A. SWINBANK, C. DAUGBJERG, The 2003 CAP Reform ..., op.cit.

30. The figure is five if Single Area Payments are counted separately. These are a variation on SFPs required initially for the new member states, who had not been in receipt of the previous direct payments which provided the base level of transfers to determine SFPs. 
the removal of the set aside obligation and introduction of other measures to preserve wildlife benefits; a simplification of the environmental cross-compliance rules for receipt of direct payments; a tightening of the exemption rules for incorporating post-1992 payments into the SFP; increases in modulation rates) are, in essence, minor changes to elements of policy already present - mainly means i changes with limited means ii changes. Even one of the more significant changes at the commodity level - the abolition of dairy quotas and an increase in the SFP - represents a means ii change as one particular Mechanism is eliminated, with a means i re-calibration of an existing Mechanism, the SFP.

\section{Conclusion}

Historical perspectives on policy require an understanding of reasons for continuity and change in that policy over time. Moreover where a policy, such as the CAP, is a complex mix of multiple institutions and instruments, explanation may be required for how and why continuity and change can be observed as occurring simultaneously. To this end, the present paper treats the CAP not as a single holistic entity but as a complex policy consisting of multiple inter-connected institutions: these are the units of analysis in CAP reform. Furthermore, it draws upon recent theoretical developments by Howlett and Cashore, which extend the earlier work of Hall on disaggregating 'policy' into different levels of analysis, distinguishing between policy ends and means. Whilst the (unchanging) goal of supporting farming incomes has remained untouched, we have shown in the paper reforms of two basic types. The first is instrument adaptation, where the prevailing instruments transferring resources to farmers are adjusted in response to pressures; and instrument innovation, where new means of supporting farm incomes are introduced or layered-in.

Second, the sources of the critical junctures leading to reform events, the triggers, were identified clearly as being budget-related, trade related, or both jointly. Early CAP reforms were budget-oriented, created by a long-term incompatibility between the obligations of a balanced budget rule, imposed on the EU budget as a whole, and the rising CAP spending created by a combination of the foundational price support instruments and the 'compulsory' nature of CAP spending. More recently, pressure has come to bear on the CAP through international trade talks, jointly with budget pressures until 'CAP reform' embedded endogenous constraints on Compulsory Expenditures. Although other factors shaping individual reforms are also identified, notably growing environmental concern within the EU, we do not find them decisive in inducing reform.

With the CAP involving the transfer of financial resources to the farm sector, critical junctures have been induced by the budgetary scale of transfers, where the fiscal consequences of the status quo were so great that the CAP had to be put onto a new financial trajectory. New institutions were layered-in that maintained support, 
as required by the Treaty of Rome, but which also stabilised spending, as required by the balanced budget rule (and also by the desire to develop spending in new policy areas whilst containing overall EU spending).

Trade-related reforms, on the other hand, were not concerned with budget spending per se but, rather, the extent to which support was channelled through tradedistorting instruments. Such reforms have not removed existing instruments from the CAP, but they have re-directed most financial resources towards new, more de-coupled, instruments layered-in to address such concerns. Reforms motivated by, notably, environmental concerns have helped determine the detailed policy response to the demands of trade talks. Moreover, the progressive layering-in of new budgetrelated instruments into CAP and EU budget institutional space has succeeded in controlling CAP spending. As a result, trade pressures are now the most likely source of future critical junctures. Trade-distorting institutions, albeit conduits of reduced financial resources to farmers, have yet to be removed from CAP institutional space.

Table 1 summarises the findings discussed at length in this paper. This reveals some important features about CAP reforms. Changes to higher-level means iii (instrument logic) or to policy ends have only occurred when one or more reform pressure was binding. The only change to policy goals (ends iii) has not involved removing existing elements, but layering-in new environmental concerns (an aspect of the CAP discussed in depth by Elton in this volume). After 1992, a number of the policy ends were reinforced in subsequent reforms but there appears to be a tailing-off in the extent to which policy ends have continued to be altered or added. Indeed, by 2009 and the Health Check the picture of changes to means $i$ and ii has taken the nature of CAP reform back to the reform episodes of the 1970s and early 1980s. Herein lies one of the most important insights offered by H\&C: significant policy change can be brought about by incremental endogenous adjustments, without the need for exogenous shocks (à la Hall); for the CAP in 2010 bears very little resemblance indeed to that of the 1970s. 
Table 1: a summary of reform means, ends, and concerns

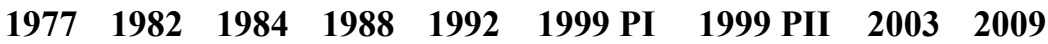

\begin{tabular}{|c|c|c|c|c|c|c|c|c|c|}
\hline B & & & $\checkmark$ & & $\checkmark$ & $\checkmark$ & $\checkmark$ & $\checkmark$ & $\checkmark$ \\
\hline $\mathrm{T}$ & & & & & $\checkmark$ & $\checkmark$ & $\checkmark$ & $\checkmark$ & $\checkmark$ \\
\hline $\mathrm{E}$ & & & & $\checkmark$ & & & $\checkmark$ & $\checkmark$ & $\checkmark$ \\
\hline ends iii & & & & & & & $\checkmark$ & & \\
\hline ends ii & & & $\checkmark$ & & $\checkmark$ & $\underline{\checkmark}$ & $\checkmark$ & $\checkmark$ & \\
\hline ends i & & & $\checkmark$ & & $\checkmark$ & $\underline{\checkmark}$ & & & \\
\hline means iii & & & & $\checkmark$ & $\checkmark$ & & $\checkmark$ & $\checkmark$ & \\
\hline means ii & $\checkmark$ & $\checkmark$ & $\checkmark$ & $\checkmark$ & $\checkmark$ & & $\checkmark$ & $\checkmark$ & $\checkmark$ \\
\hline means i & $\checkmark$ & $\checkmark$ & $\checkmark$ & $\checkmark$ & $\checkmark$ & $\checkmark$ & $\checkmark$ & $\checkmark$ & $\checkmark$ \\
\hline
\end{tabular}

Notes:

$\mathrm{B}, \mathrm{T}$ and $\mathrm{E}$ refer to, respectively, the presence of binding budget, trade and environmental reform pressures;

PI and PII reflect the two elements of the 1999 reform that addressed, respectively, Pillar I and Pillar II (see main text).

The underlined ticks indicate that these policy ends were not introduced in 1999, but were developed further in 1999, following their introduction in 1992. 


\section{Ab sofort gilt die Charta!}

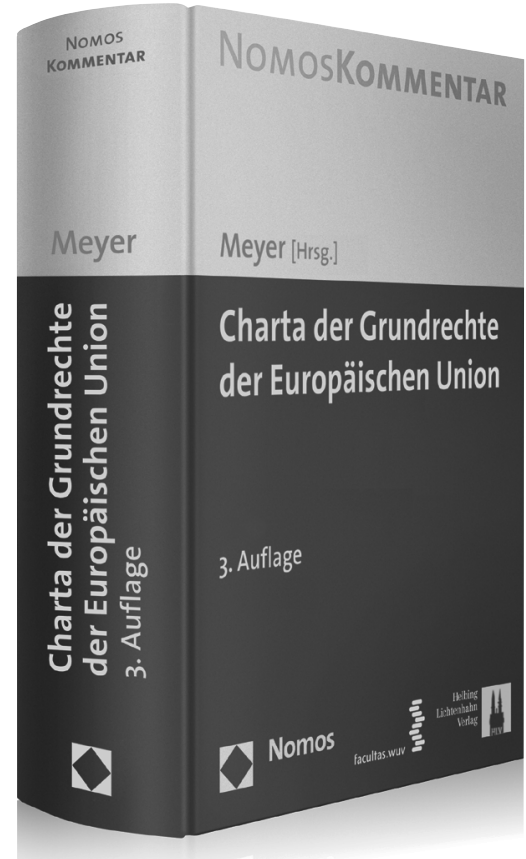

\section{Charta der Grundrechte der Europäischen Union}

Herausgegeben von

Prof. Dr. Jürgen Meyer

3. Auflage 2011, 748 S., geb., 108,- $€$ ISBN 978-3-8329-5286-O

Lieferbar!

Durch den Reformvertrag von Lissabon wird die Europäische Grundrechtecharta geltendes Recht. Sie bindet nun die Organe und Einrichtungen der Europäischen Union und die Mitgliedstaaten bei der Durchführung des Unionsrechts. In der Rechtsprechung der Unionsgerichte wie der nationalen Gerichte wird die Charta zukünftig eine wichtige Rolle spielen. Sie kann jetzt auch verstärkt bei der Auslegung nationaler Grundrechtsvorschriften herangezogen werden.

Zeitnah zum Inkrafttreten der Grundrechtecharta erscheint eine aktuelle Neuauflage des Standardkommentars. Das Werk

- erläutert die Präambel und sämtliche Artikel anhand ihrer Entstehungsgeschichte

- interpretiert die Bestimmungen der Charta für die Anwendung in der Rechtspraxis

- behandelt auch die prozessuale Durchsetzung der europäischen Grundrechte.

Ein Schwerpunkt der 3. Auflage ist das Verhältnis der Charta zur Europäischen Menschenrechtskonvention und zu den Gewährleistungen der deutschen Verfassung. Kommentiert werden insbesondere Schutzbereiche der Charta, die das Grundgesetz nicht ausdrücklich erwähnt. Alle einschlägigen Entscheidungen des EuGH, des EGMR und des Bundesverfassungsgerichts sind berücksichtigt. 


\section{"Fortress Europe" in Long-term Perspective: Agricultural Protection in the European Community, 1957-2003}

\section{Mark SPOERER}

The history of European integration is usually told as a success story. Countries that used to fight against each other for centuries decided to cooperate politically as well as economically and established supranational institutions. More than half a century after its foundation, the European Union forms an umbrella under which its member states pursue common interests or compete peacefully for resources and markets. ${ }^{1} \mathrm{At}$ least for the core of the states that joined the European Union before the turn of the century, the very idea that neighbouring states take up arms to resolve conflicts is hardly conceivable. By all political standards this is indeed a tremendous success.

This historical achievement, however, did not come without cost. As numerous states have to coordinate their decision-making, costly institutions emerged to manage the European Union. The notorious 'bureaucrats in Brussels', though, cost the European taxpayer not more than 0.06 per cent of the combined gross national income (GNI) of the EU member states. ${ }^{2}$ Even if some bureaucratic excesses may call for rationalization, the EU's political coordination costs are quantitatively negligible.

For an assessment of the true costs of the European Union it is not sufficient to consider administration costs alone. A more interesting issue is whether the policies pursued by the EU caused costs that feasible alternatives would not have had. In this respect the EU's Common Agricultural Policy (CAP) comes immediately to mind. In the first three decades of the EU it was the CAP that received by far most public attention, to an extent that the CAP seemed at times to be nearly congruent with EU politics. This was mirrored by the EU budget, the expenditure side of which was (and still is) dominated by the CAP, with its share peaking at 90 per cent in $1970 .^{3}$

Yet the CAP cost European consumers and taxpayers much more than what was visible in the EU budgets. European farmers enjoyed high protection levels against cheaper imports and even received subsidies to export their production surpluses. This may be interpreted as a huge redistribution program from the non-agricultural sectors to agriculture. In total, however, the costs borne by taxpayers and consumers were larger than the farmers' benefits because high prices crowded out consumer demand and the subsidized expansion of European agriculture bound labour and cap-

1. Throughout this article the term 'European Union' will be used for its predecessors as well: EEC European Economic Community and EC - European Community. I would like to thank the German Historical Institute Paris and the Deutsche Forschungsgemeinschaft for generous funding of this research project and Carine Germond, Fernando Guirao, Markus Hofreither, Cathérine Moreddu, Katja Seidel and Stefan Tangermann for very helpful comments on earlier drafts of this paper and Michael Buchner and Valentin Kreilinger for very able research assistance.

2. Calculated from European Commission, EU Budget 2008: Financial Report, Office for Official Publications of the European Communities, Luxembourg, 2009, pp.77-83.

3. EAGGF Guarantee Section plus related structural funds, calculated from ibid., p.78. 